\title{
Graduate AtTribute MANAgement: MAPPING UNIVERSity GeneriC ATtributes TO THOSE OF THE CANADIAN ENGINEERING ACCREDITATION BOARD
}

\author{
Samira ElAtial, Jason P. Carey ${ }^{2}$, Bashair Alibrahim ${ }^{3}$, Marnie V. Jamieson ${ }^{2}$ \\ ${ }^{1}$ Campus Saint Jean, ${ }^{2}$ Faculty of Engineering, and ${ }^{3}$ Faculty of Arts, University of Alberta \\ selatia@ualberta.ca,jpcarey@ualberta.ca, bashair@ualberta.ca,mvjamies@ualberta.ca
}

\begin{abstract}
After 2009, accredited Canadian engineering schools began to develop processes to map the Canadian Engineering Accreditation Board-Graduate Attributes (CEAB-GAs) to their curriculum and integrate ways to measure them. At around the same time, several Canadian universities embarked on a process to identify their own University-wide Graduate Attribute (UGAs). UGAs are assumed to be applicable across study disciplines; i.e. the university experience as a whole.

To address the need to assess students on the basis of the $C E A B$ GAs and the UGAs in the Faculty of Engineering and develop the basis for an integrated graduate attribute management system, an interdisciplinary team conducted a yearlong qualitative study with the purpose of exploring the intersection of the UGAs with CEAB-GAs. The key objectives were to develop a mapping process between the two sets and to explore management strategies for assessing both sets of graduate attributes. Two independent teams performed the mapping exercise using a sequential mixed methods study design. A qualitative exploratory mapping study was followed by a quantitative aggregation of the mapping results. Integration of the qualitative and quantitative study results was completed as part of the interpretation of the results. Both forward and backward mapping took place. Results demonstrated that, although generic, UGAs may not necessarily capture specific professional program graduate attributes such as the CEAB-GAs. The study also highlighted the need for more revisions and updates of UGAs by including various stakeholders who can substantially contribute to implementation and assessment of UGAs.
\end{abstract}

Keywords: University, CEAB, Graduate Attributes, Mapping Process, Assessment, Curriculum, Management

\section{INTRODUCTION}

In alignment with the internationally agreed upon Washington Accord [4], accreditation of Canadian undergraduate programs in engineering requires that students show competencies in twelve graduate attributes, as per the $\mathrm{CEAB}$ requirements.

The CEAB-GA are structured as performance-based outcomes and intended to assure graduate and program quality. The University of Alberta (U of A) Faculty of Engineering (FoE) assessment model includes Aspects (sub-attributes), Indicators, and Measurements for each of the CEAB-GA. The $\mathrm{U}$ of $\mathrm{A}$ defined seven graduate attributes for all graduating students including professional program students. From a preliminary review, the CEAB graduate attributes and the $\mathrm{U}$ of $\mathrm{A}$ UGAs did not match as demonstrated in Table 1. From a professional program perspective, the priority of the FoE is to develop competence in undergraduate engineering students to ensure the safety of the public, whom engineers serve, and maintain accreditation by meeting the governing body requirements.

\subsection{Motivation}

The overarching objective of this interdisciplinary study is to advance the scholarship in understanding, use, implementation and tailoring of discipline-specific professional skills, linking them to the interdisciplinary Graduate Attributes. This paper addresses the following questions:

- Do the UGAs align and map to the CEAB-GAs?

- How could the UGAs be revised in ways to include all other program attributes, including the CEAB?

The outcomes of this paper will be valuable toward developing an integrated and empirical cross-disciplinary standardization of UGA assessment and to those who seek to tailor UGAs to specific programs by activating this mapping model in different faculties and disciplines.

\subsection{Literature Review}

Across different disciplines and institutions, trials of implementing the GA model resulted in a number of reflections on the attributes themselves, their roles within program requirements, as well as their implementation procedure. While Spronken-Smith et al. [10] affirm that: 
"The process of embedding graduate attributes in degree programs is a substantial undertaking since it typically involves major curriculum renewal (p.264)", they highlight the importance of undertaking that mission "as a means to improve student learning [10]", and suggest it should not be driven by compliance to accreditation boards and requirements. O'Donnell et al. [8] identify, during the mapping process, two axes of progression of the transferable skills and attributes (TSA), where (1) the vertical progression "provide(s) learning experiences that enable students to develop a repertoire of skills, attributes, capabilities and learning strategies that ensure they can operate effectively and efficiently within their elected academic field of study (p. 21)"; and (2) the horizontal progression "aims at fostering certain skills and abilities that enable students to operate successfully within a variety of employment settings [9]." Accordingly, a combination of these two axes of core content and contextual knowledge repertoire and of professional, metacognitive, and adaptable skills and attributes are at the centre of every academic program. With increasing importance being placed on the coalescence of specific fundamental knowledge with flexible generic professional attributes [5], course instructors are required to integrate this approach into their course design to satisfy program objectives including graduate attributes $[2,6]$. . This highlights the necessity of mapping the generic skills to specific disciplines as an enduring process that requires follow up with programs and course instructors to document implementation challenges of the graduate attributes at the course level: "(...) something more than one shot mapping and embedding is needed to ensure that embedded graduate attribute development is continuously reviewed and renewed (p325). Bath et al [1]. ". This "fine tuning" is echoed by Easa, confirming the continuous review process should: "include the indicators, the curriculum map, and program objectives and plan [2] (p.556)." Mapping the UGAs to specific programs: "drives graduate attribute development from the merely espoused curriculum to the enacted curriculum. (p.325) [1]." The enactment of the UGAs results thus in a qualityassured curriculum. Along with course level implementation procedures, a quality assured curriculum gives way to what Bath et al. [1] call 'a living and validated curriculum'; a curriculum that is aligned with the needs and aspirations of all stakeholders, including students as well as employers.

Throughout the process of enactment of the UGAs as a central objective in higher education, the literature around implementation processes underlines the multiple procedures and challenges associated with mapping a broad set of UGAs to different programs and disciplines. Easa underscores a number of strategies that served the implementation of CEAB-GAs within an engineering program, including: "(a) continuous interaction between the Quality Assurance Director and individual working groups and representatives, (b) frequent general meetings for engineering chairs and course instructors who conduct the assessments, (c) appointment of a coordinator and working group for the science courses taught to engineering students, and (d) several retreats at both the program and faculty levels [2] (p.556)."

As a method of application of the GA model, Lawson et al. [7] distinguish two approaches the first is a "top down" method: "(...) with conduction of the mapping at the faculty management level, employing experts to develop rubrics, using independent markers to generate the data and in one case running independent standardised testing outside of the subjects;" whereas the second method is a "bottom up" approach: "asking subject coordinators to identify which graduate attributes map to their subjects, encouraging academics to develop assessment rubrics, getting lecturers to mark assessment for subject specific and generic attributes [7]". On the other hand, Oliver focuses on the challenges of the implementation of the GA model, indicating that while:

"mapping the curriculum can be useful in identifying where skill development has been overlooked (...) it can also be a negative exercise for academics, particularly if they (...) see it as threatening or an administrative burden [9] (p.454)."

This paper comes as an extension to the previous body of research on implementing UGAs, and their interaction with other program specific requirements such as the CEAB-GAs. So far, there has been substantive research on the UGAs, their development, pertinence, stakeholders' perception, and implementation. Similarly, and independently, the body of research within engineering education on the CEAB-GAs has been substantially investigated. However, relevant research that bridge the two set of attributes is lacking. This paper is an attempt to map the two sets of attributes.

\subsection{Problem Definition}

In order to address multiple requirements for student assessment to meet accreditation standards, professional requirements, and university graduate attribute targets, an interdisciplinary qualitative study was proposed. The purpose of the yearlong team collaboration was to explore the intersection of the UGAs with CEAB-GAs, to develop a mapping process between the two graduate attribute sets, and to explore management strategies for assessing both sets of graduate attributes.

\subsection{Solutions Considered}

An integrated solution to manage the two sets of graduate attributes with overlapping yet distinct criteria and drivers is desired and the end result of the work in progress. Alternatively, managing two graduate attribute assessment systems for engineering students would be 
required. This was rejected on the basis of additional workload at the administration, instructor, and student level. The anticipated level of front line stakeholder commitment to two graduate attribute assessment systems is low. The work reported in this paper is the exploratory step to understand the intersection of the two sets of graduate attributes in support of an integrated solution.

\subsection{Selected Methodologies}

Two independent teams performed the mapping exercise using a sequential mixed methods study design. A qualitative exploratory mapping study was followed by a quantitative aggregation of the mapping results. Integration of the qualitative and quantitative study results was completed as part of the interpretation of the results. Both forward and backward mapping took place.

\subsection{Significance of the results}

Generic, UGAs may not necessarily capture specific professional program graduate attributes such as CEABGAs. As a result, the integration of measurement and reporting of the CEAB GAs and UGAs is not a simple process. In addition, the needs of stakeholders requiring professional accountability may differ from those driving funding accountability.

\section{MIXED METHODS MAPPING PROCESS}

Over a period of seven months, various meetings were held with representatives from all university faculties, including separate program specific meetings. In addition, a general retreat offered the opportunity to exchange experiences and discuss the challenges faced by each program during the process of mapping the UGAs to the required professional attributes. The purpose of these meetings helped the larger cross disciplinary university team grasp a macro understanding of the UGAs as university-wide attributes, and a micro-understanding of professional graduate attribute requirements for specific programs such as the Faculties of Medicine, Rehab Medicine, Education, and Engineering. CEAB-UAG mapping was planned and completed for Engineering by a team experienced with the CEAB-GAs and UGAs and further elucidated in this work.

The mapping exercise was performed by two teams: the first group is composed of three members of the Faculty of Engineering, all of whom are subject-matter experts familiar with the CEAB-GAs and their assessment within the context of an engineering program. The second group is composed of two external members who were extensively researching the assessment and implementation of the UGAs. In this way, the teams are complimentary and can have an objective arms-length evaluation of the process. Both teams worked on the two sets of attributes presented in Table 1 .
For each of the twelve CEAB-GAs, the FoE had previously defined a list of sub-attributes, which constitute the key aspects of the graduate attribute. For each one of these sub-attributes, Indicators had also been defined, which describe what a student must do to show competency in the attribute. Where possible, indicators were common across all nine engineering programs in the faculty; but where necessary, program-specific indicators were used. When assessing students, performance was rated on a 4-level scale based on a descriptive rubric.

Table 1: University and CEAB Graduate Attributes.

\begin{tabular}{|l|l|}
\hline UGA (7) & CEAB-GA (12) \\
\hline $\begin{array}{l}\text { Ethical Responsibility. } \\
\text { ER }\end{array}$ & Knowledge base in engineering-KB \\
\hline Scholarship-SC & Problem analysis -PA \\
\hline Critical Thinking-CT & Investigation -IN \\
\hline Communication-CM & Design -DE \\
\hline Collaboration-CL & Use of Engineering tools-ET \\
\hline Creativity-CR & Individual and team work.TW \\
\hline Confidence-CF & Communication skills-CS \\
\hline & Professionalism-PR \\
\hline & $\begin{array}{l}\text { Impact of engineering on society } \\
\text { and environment-IS }\end{array}$ \\
\hline & Ethics and equity-EE \\
\hline & $\begin{array}{l}\text { Economics and project } \\
\text { Management -EP }\end{array}$ \\
\hline & Lifelong learning-LL \\
\hline
\end{tabular}

Each of the seven UGAs have four sub-attributes. During development of a criteria-based model for assessing UGAs, specific interpretations in the form of can-do statements were developed for each sub-attribute, along with descriptive rubrics for a 5-level rating scale to describe relative levels of attribute acquisition [3]. The structure of these statements bears a close resemblance to the indicators and assessment rubrics that have been written for the engineering sub-attributes and CEABGAs.

To map the CEAB-GAs to the UGAs, each FoE indicator was compared to the list of can-do statements and associated rubrics used to describe the UGAs subattributes. Related sub-attributes and can-do statements were linked to the indicator in question as shown for example in Table 2 below. If appropriate, a single UGA 
sub-attribute could be assigned to multiple different FoE indicators, and multiple UGA sub-attributes could be linked to a single FoE indicator. If none of the can-do statements were appropriate, the indicator mapping was left blank.

Table 2: Sample graduate attribute mapping table.

\begin{tabular}{|c|c|c|}
\hline \multicolumn{3}{|c|}{ CEAB-GA \#10: Ethics and Equity } \\
\hline \multicolumn{2}{|c|}{ Faculty of Engineering } & \multirow{2}{*}{$\begin{array}{l}\text { University } \\
\text { Sub-attribute (Can-do statement) }\end{array}$} \\
\hline $\begin{array}{l}\text { Sub- } \\
\text { attribut }\end{array}$ & Indicator & \\
\hline $\begin{array}{l}\text { Awareness } \\
\text { of Ethical } \\
\text { Issues }\end{array}$ & $\begin{array}{l}\text { Feels confident in } \\
\text { ability to address } \\
\text { ethical dilemmas }\end{array}$ & $\begin{array}{l}\text { 1a. Global citizenship } \\
\text { 1b. Community engagement } \\
\text { 1c. Social and environmental awareness } \\
\text { 1d. Professionalism }\end{array}$ \\
\hline $\begin{array}{l}\text { Code of } \\
\text { Ethics }\end{array}$ & \begin{tabular}{|l|} 
Identifies \\
provisions of the \\
APEGA Code of \\
Ethics \\
\end{tabular} & $\begin{array}{l}\text { 1d. Professionalism (Is willing to meet } \\
\text { the level of expertise and deontological } \\
\text { expectations of her intended profession) }\end{array}$ \\
\hline $\begin{array}{l}\text { Makes } \\
\text { Ethical } \\
\text { Choices }\end{array}$ & $\begin{array}{|lr|}\text { Makes } & \text { ethical } \\
\text { choices } & \text { in } \\
\text { complex } & \text { situations }\end{array}$ & $\begin{array}{l}\text { 1a. Global citizenship } \\
\text { 1b. Community engagement } \\
\text { 1c. Social and environmental awareness } \\
\text { 1d. Professionalism }\end{array}$ \\
\hline $\begin{array}{l}\text { Awareness } \\
\text { of Equity } \\
\text { Issues }\end{array}$ & \begin{tabular}{|l|} 
Identifies \\
situations \\
containing equity \\
issues
\end{tabular} & $\begin{array}{l}\text { 5a. Openness to diversity (Can engage } \\
\text { with a diversity of people (in terms of } \\
\text { race, religion, cultures, classes, sex } \\
\text { orientation and appearance) }\end{array}$ \\
\hline $\begin{array}{l}\text { Awareness } \\
\text { of Equity } \\
\text { Issues }\end{array}$ & $\begin{array}{l}\text { Is aware of } \\
\text { provisions } \\
\text { the within } \\
\text { Human } \quad \text { Alberta } \\
\text { Citizenship ands, } \\
\text { Multiculturalism } \\
\text { Act }\end{array}$ & 5a. Openness to diversity \\
\hline $\begin{array}{l}\text { Awareness } \\
\text { of Equity } \\
\text { Issues }\end{array}$ & $\begin{array}{l}\text { Feels confident in } \\
\text { ability to address } \\
\text { equity }\end{array}$ & 5a. Openness to diversity \\
\hline
\end{tabular}

The steps in the mapping process were as follows:

1. Preparatory phase: This phase consisted of various meetings with several groups. The first meeting was an informative one. The purpose of the second meeting was a team calibration retreat of two days where various groups representing various faculties met to discuss their own programs, their involvement with their program specific requirements and the UGAs and the challenges they face with the implementation of these. The third meeting was to draft working documents and identify working groups and subgroups, as well as task for individual members.

2. Analysis phase: Separate and group analyses were conducted. Each member in each group conducted the mapping exercise. Some members carried the forward mapping, i.e. CEAB-GAs to UGAs, and others the backward UGAs to CEAB-GAs.
3. Reviewing phase: each subgroup within the group analyzed their results and each provided reviews to the other members. Aggregate tables were created, and discrepancies amongst evaluators were discussed. A standard setting process was carried out to ensure the final reports of each group met all members' evaluations. Both convergences and divergences were documented.

4. Debriefing phase: Final tables of mapping were shared and comparisons amongst groups were carried out. Final adjustments to the mapping were done.

\section{RESULTS AND ANALYSIS}

When performing the mapping, all Faculty-wide indicators were mapped first, followed by any programspecific indicators. In total 187 engineering indicators were mapped to the 28 University sub-attributes. Of the engineering indicators, 72 were common to all programs, and 115 were program-specific.

Mapping the CEAB-GAs to the UGAs produced a table for each CEAB-GA linking CEAB-GA FoE indicators to corresponding UGA sub-attributes. As a representative example, CEAB-GA Ethics and Equity was selected. EE intersected with two UGAs, Ethical Responsibility and Collaboration, as demonstrated in Table 2. For example, consider the UGA indicator for the CEAB-GA EE: Feels confident in ability to address ethical dilemmas, which is measured by a survey questions at program entrance and exit. $U$ of $A$ engineering programs provide a variety of learning activities and courses intended to develop student ability to address ethical dilemmas including design, ethics, safety and risk management. This indicator and measurement for EE encompassed the ER sub-attributes of global citizenship, community engagement, social and environmental awareness, and professionalism. The following were the key findings resulting from the GA mapping exercise:

First, there is little in the UGAs that relates to the CEAB-GA for "Knowledge Base", as evidenced by the single match indicated in Table 2. The only link found was related to the UGAs for "Scholarship", of which only a single sub-attribute was able to be mapped. This finding was not surprising, as the UGAs framework was designed to be broad in order to encompass all university programs, whereas the indicators defined for the CEAB-GA tend to be targeted towards highly discipline-specific knowledge.

It was found that no UGAs explicitly dealt with the use of tools to accomplish a task, which led to limited mapping opportunities with the "Use of Engineering Tools" CEAB-GA. One UGAs sub-attribute from each of $\mathrm{CM}$ and $\mathrm{CR}$ were mapped, but neither UGA could be fully aligned. This is an important omission from the 
UGAs that should be addressed, as the ability to use modern tools is a key part of the University experience shared by students of all Faculties that should be valued by the University.

Another important oversight observed was that none of the UGAs considered time management, economics, project management, or financial literacy. As a result, there was nothing that could be mapped to the "Economics and Project Management" CEAB-GA. It can easily be argued that these attributes are vital to all university graduates, who will require knowledge and skills in economics and project management in both their personal and professional lives, and that an additional UGAs should be added to reflect this.

The UGA "Communication: Multilingualism" has been interpreted during this mapping process to include computer languages and technical drawings. These are important "languages" that are used to accomplish tasks and communicate ideas within an engineering context. At the time of the mapping process, the CEAB did not recognize language courses as part of engineering curricula, and such there could be no link to multilingualism in a more conventional sense. This changed in 2018; CEAB now recognizes languages as complementary studies electives. However, it should be noted that multilingualism will not be an engineering learning outcome or indicator in communication skills, allowing students to make their own choice of complementary studies course is an important principle of the programs.

The UGAs "Creativity: Imagination" is described by the statement "Can conjure up new ideas and representations in a productive manner." This group could not reconcile the use of "conjure up", as it has the connotation of "pulling something out of thin air", rather than generating ideas based on facts, reason or experience. It is understood that the UGA attempts to bring an emotional perspective to Creativity: Imagination, which is important but requires a refined definition in order to apply more universally.

The description of the UGAs "Creativity: Divergent thinking" could also be improved. This UGA is described by the statement "Can explore new avenues in a nonconformist and risk-taking fashion." The group agreed that thinking in a "risk-taking" fashion is not necessarily something that all $U$ of A graduates should strive for, particularly when mitigation of risk is often of high importance in a field such as engineering. For the purposes of the mapping exercise, this was interpreted as "outside the box" thinking.

One final UGA definition that could be improved is the statement "Can be compelled by artistic work and, ideally, partake in expressive artistic production," used to describe the UGA "Creativity: Artistic sensibility". We believe that rather than "compelled by artistic work", the focus should be on being able to "appreciate and contribute to artistic work", as this is more widely applicable to students in all areas of study across the University.

An ancillary benefit of the mapping process was that it allowed the Engineering group the opportunity to further reflect upon and refine the current CEAB-GA Aspects and Indicators being used for assessment. As a result, a number of potential improvements to the list of aspects and indicators were identified and recorded to be considered for future implementation by the affected engineering programs.

\section{DISCUSSION}

During this process, it became evident that for the success of such exercise, certain elements are important for consideration. Training is important for all individuals involved in the mapping. Stakeholder perspective must be taken into consideration during the process. A forward and backward mapping is useful to ensure that all perspectives are met. In order to ensure objectivity and validity, it is important to have two sets of evaluators: those heavily involved with specific programs who are extensive experience and knowledge about the discipline specific attributes, and those content experts who have expertise in the university-wide graduate attributes. Both sets of evaluators must understand the objectives of both sets of graduate attributes in order to meaningfully map them.

The mapping process has been mostly qualitative in nature. In total, 13 individuals took part in various parts of the process. For future studies, it is recommended that reliability studies be carried out with a larger pool of evaluators/mappers, and it is equally important to replicate the study to other programs and institutions in order to statistically compare and analyze findings and results.

There are two important items for consideration: it would be of utmost importance for the validity of the mapping process to include instructor and student feedback. We realize that this is a difficult task and we need to find ways to address it. Second, the university central administration must have an active role in the mapping process to inform and ensure a concrete implementation of the UGAs in programs. Unless these groups are actively involved, any attempts to truly demonstrate achieving UGAs throughout the institution will remain elusive.

\section{CONCLUSIONS}

The mapping process carried out for this project was a timely and illuminating task. During the exercise, it became evident that any possible implementation of the UGA assessment of and their possible assessment?? 
cannot be achieved from a macro level, but every program needs to be involved in order to truly understand and adapt the UGAs to program specific curriculum and objectives. A constant interaction between university wide administrators and specific programs is necessary to truly understand and address thee UGAs. Equally important is the ground-up substantive work that program can carry out in order to provide a micro-level mapping to a much larger university macro-level.

\section{Acknowledgements}

This project has been funded by a research team grant from the Kule Institute for Advanced Study in interdisciplinary research at the University of Alberta. A complete report on this work has recently been published in the Canadian Journal of Higher Education - Revue canadienne d'enseignement supérieur [12].

\section{References}

[1] D. Bath, C. Smith, S. Stein, and R. Swann, "Beyond mapping and embedding graduate attributes: bringing together quality assurance and action learning to create a validated and living curriculum," Higher Education Research and Development, vol. 23 no. 3 pp. 313-328, 2004.

[2] S. M. Easa, "Framework and guidelines for graduate attribute assessment in engineering education," Canadian Journal of Civil Engineering, vol. 40 no.6, pp.547-556, 2013.

[3] D. Ipperciel and Samira ElAtia, "Assessing Graduate Attributes: Building a Criteria-Based Competency Model," The International Journal of Higher Education, vol. 3 no.4, pp. 27-39, 2014.

[4] International Engineering Alliance (IEA), Best Practice in Accreditation of Engineering Programs: an Exemplar, 2015. IEA.

[5] Marnie V. Jamieson and John M. Shaw, "Graduate Attribute Based Continuous Course Improvement in a Blended Learning Engineering Design Course - A Writing Seminar Case Study," Canadian Engineering
Education Association (CEEA 2018) Conf., Paper 77, Vancouver, BC; June 3-6, 2018.

[6] M.V. Jamieson and J.M. Shaw, "Teaching engineering for a changing landscape," The Canadian Journal of Chemical Engineering vol. 97 no. 11, pp. 2870-2875, 2019.

[7] R. Lawson, T. Taylor, E. Fallshaw, E. French, C. Hall, S. Kinash, and J. Summers, Hunters and gatherers: Strategies for curriculum mapping and data collection for assuring learning (Final Report), Office for Learning and Teaching. Dept. of Industry, Innovation, Science, Research and tertiary Education, 2013, pp. 10-109,

[8] P. O'Donnell, B. Rakhshani, A. Rae, and R. Smith, "The Adaptable Graduate," Graduate Attributes in Higher Education: Attitudes on Attributes from Across the Disciplines, 19-38, 2017.

[9] B. Oliver, "Graduate attributes as a focus for institution-wide curriculum renewal: innovations and challenges," Higher Education Research \& Development, vol. 32 no.3, pp. 450-463, 2013.

[10] R. Spronken-Smith, C. Bond, and A. Mclean Institutional Toolkit for Engaging with Graduate Outcomes, 2015. Available as of March 1, 2020, from https://akoaotearoa.ac.nz/download/ng/file/group5324/institutional-toolkit-for-engaging-with-graduateoutcomes.pdf

[11] R. Spronken-Smith, A. McLean ,N. Smith, C. Bond, M. Jenkins, S. Marshall, and S. Frielick, "A toolkit to implement graduate attributes in geography curricula," Journal of Geography in Higher Education, vol. 40 no.2, pp., 254-266, 2016.

[12] Samira ElAtia, Jason P. Carey, Marnie V. Jamieson, Bashair AliBrahim \& Marcus Ivey. "Intersecting Roadmaps: Resolving Tension Between ProfessionSpecific and University-Wide Graduate Attributes" Canadian Journal of Higher Education Revue canadienne d'enseignement supérieur vol. 51 no.1 pp. 71-98, 2021. 